\title{
PRESENTACIÓN II DE REFLEXIONES SOBRE POLÍTICA $Y$ CULTURA EN LATINOAMÉRICA. MARCOS GARCÍA DE LA HUERTA, LECTURAS Y DESLECTURAS
}

\author{
Carlos Peña \\ Universidad Diego Portales \\ Universidad de Chile
}

Son varias las virtudes del libro que, relativo a la obra de Marcos García de la Huerta, estamos ahora presentando.

La primera de esas virtudes es que este libro recoge un tipo de trabajo intelectual que se resiste a lo que parece ser el estilo predominante que, poco a poco, comienza a anegar a las instituciones universitarias. La segunda es que en él se exhibe una forma de ejercer la filosofía que la entrevera con el mundo que tenemos delante. La tercera es que en él se dialoga en torno a un conjunto de problemas que, desplegados en la obra de Marcos García de la Huerta, constituyen también una agenda de trabajo para la filosofía política en su conjunto.

Permítanme examinar brevemente cada una de esas virtudes en el mismo orden en que las acabo de enunciar.

Las universidades contemporáneas, como todos ustedes saben, viven ocupadas, ante todo, de avanzar en los rankings y para ello se esmeran en producir publicaciones indexadas cuyo valor, aquello que se persigue con esmero, no está dado por el contenido de las publicaciones o el diálogo a que ellas dan lugar, sino por el número y el impacto cuantitativo que producen. En un texto sencillo y breve, La tiranía de los valores (1960), Carl Schmitt auguró que en un mundo donde todo se mide el valor desaparece. Algo así aqueja, como un peligro, a las universidades contemporáneas que como consecuencia del fenómeno acerca del que llamo la atención, transforman las publicaciones, que debieran ser el acto intelectual por antonomasia, en un acto cuyo sentido está en el simple hecho de lograr ser incluidas en un índice. La mera performatividad, el sentido de la acción intelectual reducida al simple hecho de su ejecución y con prescindencia de su contenido, amenaza, cada vez más, con ser el destino del quehacer intelectual en la universidad contemporánea.

Afortunadamente hay universidades y profesores, y entre ellos, claro, se cuentan, a juzgar por este libro, los de la Universidad Academia de Humanismo Cristiano, que se resisten a ese destino y en vez de esmerarse en fabricar solo publicaciones indexadas, en lugar de solo seguir la guia del dispositivo técnico instalado hoy en las universidades, prefieren seguir publicando libros en los que se contienen trabajos que aspiran a recobrar, para el trabajo intelectual, el desasosiego de la crítica y el diálogo. $\mathrm{Y}$ esta es, por supuesto, la primera virtud, como digo, del trabajo que ahora estamos presentando: ser un esfuerzo de reflexión que va a contrapelo de un estilo de trabajo 
intelectual que, si se le deja a sus anchas sin moderación alguna, sin oponerle ningún esfuerzo en contrario, sin dibujar ninguna orilla que lo detenga, acabará dañando la tarea intelectual y la propia filosofía.

Pero si este libro, como acabo de decir, tiene la virtud de ejercitar un estilo de trabajo intelectual que se resiste a las tentaciones de la hora, posee todavía otra y esta consiste en que en él se ejercita, tanto por la obra que en él se analiza, como por los análisis que a ella se refieren, una específica forma de hacer filosofía.

En efecto, los trabajos de Marcos García de la Huerta están todos ellos inspirados por la convicción de que hacer filosofía no consiste en moverse con agilidad en el cielo de los conceptos o transitar como Pedro por su casa por la historia de la filosofía o conocer, hasta sus últimos intersticios, los accidentes genealógicos de los conceptos y las palabras que usan los filósofos, sino que filosofar consiste en echar mano a todo lo anterior para pensar la época que al filósofo le ha tocado en suerte. El filósofo no es así quien se distrae de las penurias de la realidad en busca de una realidad subyacente y quieta que, alojada en los conceptos, permite consolarse de los defectos de la primera, sino que el filósofo, y este es el ejemplo de García de la Huerta, es quien llama a capítulo a la realidad para preguntarle cómo es que llegó a ser lo que ahora es y descubrir, entonces, que a pesar de toda la rotundidad que exhibe, ella podría ser, sin embargo, distinta. Toda la obra de Marcos García de la Huerta está asistida por la convicción de que el tiempo que al filósofo le toca vivir no es una realidad quiescente o fija, una realidad independiente del pensamiento que a ella se refiere, sino que una realidad hasta cierto punto modelada por el discurso humano, de manera que los esfuerzos de la filosofía deben encaminarse a comprender de qué forma debió concebirse la realidad para que ella alcanzara la fisonomía que hoy día posee. Por eso, sin exageración puede afirmarse que cuando Marcos García de la Huerta se ocupa de historia o de historiografía, de Góngora o Edwards o Bello, o de la técnica o de política, del Bicentenario o del 91, está haciendo en verdad la más estricta filosofía, porque el filósofo es capaz de apreciar de qué forma la realidad está moldeada por el discurso que ejerció sobre ella un efecto performativo y por eso, es todavía capaz de ver en la realidad-como realidad, según subrayó alguna vez Patricio Marchant- el pensamiento de otros.

Pero si ejercitar un tipo de trabajo universitario y una forma de hacer filosofía, que son los rasgos que acabo de identificar, son motivos más que suficientes para celebrar este libro, hay que agregar todavía que en él, y a propósito de la obra de García de la Huerta, se discuten un conjunto de temas que, en un sentido amplio, forman parte de lo que podríamos denominar filosofía política en situación. El libro acredita hasta qué punto García de la Huerta es, para usar la expresión que se acuñó en los sesenta, un filósofo en situación. Un filósofo en situación, se decía por esos años - pero perfectamente puede seguirse diciendo hoy día- es quien tiene una conciencia aguzada de su circunstancia, la que se revela ante él como deficitaria, como una realidad carente o en deuda, de manera que ante ella el filósofo se ve puesto en la necesidad de escudriñar cómo llegó a constituirse esa carencia y a investigar de qué forma en la misma realidad carente, se encuentra oculta, subyacente, la receta para remediarla. 
¿Cuáles son los temas que entrecruzan y animan el diálogo de este libro y que la obra de García de la Huerta saca a la luz?

No tenemos tiempo, por supuesto, de examinarlos en detalle; pero alguna mención, siquiera genérica, resulta indispensable.

Se encuentra ante todo el problema de la universalidad de la razón, que es uno de los temas que, en este diálogo, plantea José Santos. Se trata de averiguar si acaso existe algún vínculo entre el valor de verdad de un discurso y el lugar de su enunciación o, si ustedes prefieren, y en términos más amplios, se trata de examinar si acaso media alguna relación entre el grado de validez de un enunciado y el contexto en el que se profiere. La obra de García de la Huerta está animada por la convicción de que hacer filosofía -no enseñar filosofía en el sentido academicista de la expresión, sino hacerla; no exponer sino pensar- consiste en entreverarse con el lugar y el tiempo donde el discurso filosófico se profiere. Este no sería un simple mandato ético del filósofo, sino una exigencia que proviene de la índole del filosofar que no debe olvidar nunca que si tiene una pretensión de universalidad ella siempre se ejecuta, lo quiera o no el filósofo, desde una particularidada la que la filosofía también llama a capítulo.

A lo anterior se suma lo que García de la Huerta llama, en uno de sus trabajos, el despertar del sueño metafísico, o lo que Jorge Vergara, siguiendo la denominación que se ha acuñado en la literatura, denomina la filosofía postmetafísica. Este fenómeno sería el producto de una ruptura y del intento de reflexionar sobre ella. El golpe militar de 1973 y la revolución capitalista que le siguió serían esa ruptura, y habrían mostrado que la realidad era contingente y que no había ninguna presencia subyacente que la garantizara. Paradójicamente entonces ese evento o acontecimiento que negó explícitamente la política, constituye la muestra más palmaria de la contingencia del mundo y del lugar consiguiente que en él tiene la política y, por supuesto, la filosofía que hace de ella el objeto predilecto de su reflexión.

La política, a su turno, es pensada por García de la Huerta como un quehacer autónomo, que, siguiendo a Arendt, se diferenciaría de lo social o de lo que hoy día, con expresión al uso, llamaríamos políticas públicas. La política para García de la Huerta es, incluso cuando se la niega, una acción constituyente del mundo que tenemos en común. Por eso, en su opinión, reflexionar sobre la política no consiste en pensarla normativamente, al modo digamos en que gustan pensarla Rawls o Nozick, sino que consiste en indagar la forma en que la acción política va configurando hasta cierto punto el mundo de la vida. De ahí entonces que García de la Huerta no conciba los derechos humanos como un a priori de la política, sino como el resultado de una comunidad política cuyos miembros se piensan a sí mismos como iguales. Por eso, y como con ánimo polémico recuerda Mauricio Suárez, García de la Huerta ha afirmado en uno de sus textos que es mejor tener derechos civiles que ser un mero titular de derechos humanos.

Y, por supuesto, si la política es constituyente del mundo y si la ruptura mostró que no había una presencia subyacente que garantizara la realidad que teníamos ante los ojos, de ahí se sigue entonces que la historiografía debe ser un objeto privilegiado de la reflexión filosófica. Y es que, al contrario de lo que nos gusta creer, la historia no 
se refiere, en verdad, a lo que ya pasó y que hemos dejado atrás definitivamente, sino, por el contrario, la historia se refiere a lo que está ocurriendo y que nos acompaña como si fuera una sombra. Entre la autocomprensión política, la forma en que la comunidad se concibe a sí misma, y la conciencia histórica, la manera en que por decirlo así vemos lo que fuimos, existe una relación indisoluble: somos nuestros recuerdos, pero ellos son a la vez una forma de reaccionar frente al tiempo que nos tocó en suerte, y ambos, entrelazados, nos constituyen erigiéndose, como explica García de la Huerta en su diálogo con Cecilia Sánchez, en el punto ciego de las filosofías del sujeto. La historia cuenta así con un auditorio doble, con dos tipos de interlocutores, a saber: el gremio de los historiadores, que juzgarán cuán adecuadas al sistema de fuentes son las averiguaciones, y el público en un sentido kantiano o político, que juzgará, por su parte, cuánta justicia hace la reconstrucción del pasado a los actuales ideales, a la comprensión que tenemos hoy día de nosotros.

Hay pocos filósofos cuya obra haya abarcado todos esos temas como lo ha hecho García de la Huerta y que, además, como él, los hayan enlazado tan bien, mostrando que la identidad de las personas y los pueblos es el resultado de capas superpuestas, de una reflexión sobre la reflexión, de una escritura sobre la escritura, de una interpretación sobre otra interpretación, sin que nunca, desgraciada o afortunadamente, podamos leer el original. 